\title{
THERMAL AND MICROSTRUCTURAL ANALYSIS OF THE LOW-MELTING Bi-In-Pb ALLOY
}

\author{
Dragan Manasijevicic ${ }^{1 *}$, Ljubiša Balanovićl ${ }^{1}$, Tamara Holjevac Grgurić ${ }^{2}$, \\ Milan Gorgievski ${ }^{1}$, Ivana Marković ${ }^{1}$, Vladan Ćosović ${ }^{3}$, Milena Premović, \\ Duško Minić ${ }^{4}$ \\ ${ }^{1}$ University of Belgrade, Technical Faculty in Bor, Bor, Serbia \\ ${ }^{2}$ University of Zagreb, Faculty of Metallurgy, Sisak, Croatia \\ ${ }^{3}$ University of Belgrade - Institute of Chemistry, Technology and Metallurgy, Belgrade, \\ Serbia \\ ${ }^{4}$ University of Pristina, Faculty of Technical Sciences, Kosovska Mitrovica, Serbia
}

Received 13.09.2020

Accepted 15.10.2020

\begin{abstract}
Low-melting alloys, based on bismuth and indium, have found commercial use in soldering, safety devices, coatings, and bonding applications. In this respect, the accurate knowledge of their thermal properties such as melting and solidification temperatures, latent heat of melting, supercooling tendency, etc. is of large importance. In the present research, low-melting alloy with nominal composition $\mathrm{Bi}_{40} \mathrm{In}_{40} \mathrm{~Pb}_{20}$ (at. \%) was investigated by means of scanning electron microscopy (SEM) with energy dispersive Xray spectrometry (EDS) and by differential scanning calorimetry (DSC). Microstructural and chemical (SEM-EDS) analysis has revealed the existence of two coexisting phases in the prepared alloy, which was identified as BiIn and $(\mathrm{Pb})$. Melting and solidification temperatures and the related heat effects were measured by the DSC technique. The solidus temperature obtained from the DSC heating curves was $76.3^{\circ} \mathrm{C}$ and the solidus temperature obtained from the corresponding DSC cooling runs was $61.2{ }^{\circ} \mathrm{C}$. The experimentally obtained results were compared with the results of thermodynamic calculation according to CALPHAD (calculation of phase diagram) approach, and a close agreement was noticed.
\end{abstract}

Keywords: $\mathrm{Bi}-\mathrm{In}-\mathrm{Pb}$ system; low-melting alloy; SEM-EDS, DSC.

${ }^{*}$ Corresponding author: Dragan Manasijević, dmanasijevic@tfbor.bg.ac.rs 


\section{Introduction}

Low-melting point alloys (LMPA), which typically contain indium, bismuth, lead, and tin, melt at temperatures less than $100{ }^{\circ} \mathrm{C}$. These alloys are required for a wide variety of applications, including step soldering, thermal fuse application, rapid prototyping, die casting, mercury replacement, thermal cooling, heating designs, and soft solder formulation [1]. They also represent promising candidates for metallic phase-change materials (PCMs) for thermal storage (TS) [2-3]. However, important thermophysical properties such as melting point, latent heat of fusion, specific heat capacity, and thermal conductivity for many low-melting alloys are still not entirely known [4].

The aim of the present study is an experimental and analytical investigation of the microstructure and melting behavior of the low-melting $\mathrm{Bi}_{40} \mathrm{In}_{40} \mathrm{~Pb}_{20}$ (at.\%) alloy. The composition of the investigated alloy was selected based on the phase diagram of the BiIn-Pb ternary system. According to the previous experimental investigations of Stel'mack et al. $[5,6]$, the InBi-Pb vertical section is a quasi-binary system with eutectic reaction $\mathrm{L} \rightarrow \mathrm{BiIn}+(\mathrm{Pb})$ at $76{ }^{\circ} \mathrm{C}$ and eutectic composition close to 20 at. $\%$ of $\mathrm{Pb}$. Microstructure, alloy composition, and coexisting phases in the solidified alloy were investigated using SEM-EDS while melting interval and heat of fusion were experimentally determined by DSC analysis. The obtained experimental results were compared with the results of thermodynamic calculation according to the CALPHAD approach.

\section{Experimental}

Ternary alloy with the nominal composition $\mathrm{Bi}_{40} \mathrm{In}_{40} \mathrm{~Pb}_{20}$ (at.\%) was prepared by melting weighted pieces of pure elements (Bi 99.999\%, In 99.999\%, $\mathrm{Pb} 99.99 \%$, Alfa Aesar) in an evacuated quartz tube. The sample was heated at $600{ }^{\circ} \mathrm{C}$ for $30 \mathrm{~min}$. The melt was stirred by shaking the quartz tube several times to ensure the homogenization of the molten alloy and slowly cooled inside the furnace. The total mass of the prepared sample was about $3 \mathrm{~g}$, while the total mass loss was less than 1 mass\%.

TESCAN VEGA3 scanning electron microscope (SEM) with energy dispersive spectrometer (EDS) (Oxford Instruments $\mathrm{X}$-act) was used for microstructural investigation. SEM-EDS analysis of the prepared ternary alloy was carried out at an accelerating voltage of $20 \mathrm{kV}$. Overall composition and compositions of coexisting phases were determined using EDS area and point analysis. All SEM images of the microstructures were taken on the polished surfaces of the studied alloy samples in backscattered electron mode.

Phase transition temperatures and corresponding heat effects were determined by simultaneous thermal analyzer STA NETZSCH Jupiter 449. The sample weighing about $40 \mathrm{mg}$ was investigated by performing three heating/cooling cycles using the heating/cooling rate of $5{ }^{\circ} \mathrm{C} / \mathrm{min}$ in the temperature interval from room temperature up to $120^{\circ} \mathrm{C}$. The reference material was empty alumina crucible. Prior to DSC measurements, temperature and enthalpy calibrations were performed using the pure metal standards (In and $\mathrm{Zn}$ ) under the measurement conditions. 


\section{Thermodynamic calculation}

Thermodynamic calculations of phase equilibria were carried out using CALPHAD (calculation of phase diagrams) approach [7]. The calculations were performed using optimized thermodynamic parameters from Boa and Ansara [8].

The solid phases from the constitutive binary subsystems considered for thermodynamic calculations of the $\mathrm{Bi}-\mathrm{In}-\mathrm{Pb}$ phase equilibria are listed with their respective crystallographic data [9] in Table 1.

Table 1. Considered solid phases in the Bi-In-Pb ternary system with their crystallographic data [9].

\begin{tabular}{lllll}
\hline $\begin{array}{l}\text { Binary } \\
\text { system }\end{array}$ & Phase & $\begin{array}{l}\text { Phase name in the } \\
\text { thermodynamic } \\
\text { database }\end{array}$ & $\begin{array}{l}\text { Pearson } \\
\text { symbol }\end{array}$ & $\begin{array}{l}\text { Strukturbericht } \\
\text { designation }\end{array}$ \\
\hline $\mathrm{Bi}-\mathrm{In}, \mathrm{Bi}-\mathrm{Pb}$ & $(\mathrm{Bi})$ & RHOMBO_A7 & $h R 2$ & $A 7$ \\
$\mathrm{Bi}-\mathrm{In}, \mathrm{In}-\mathrm{Pb}$ & $(\mathrm{In})$ & TETRAG_A6 & $t I 2$ & $A 6$ \\
$\mathrm{Bi}-\mathrm{In}$ & $\mathrm{BiIn}$ & BIIN & $t P 4$ & $B 10$ \\
$\mathrm{Bi}-\mathrm{In}$ & $\mathrm{Bi}_{3} \mathrm{In}_{5}$ & BI3IN5 & $t I 32$ & $D 8_{1}$ \\
$\mathrm{Bi}-\mathrm{In}$ & $\mathrm{BiIn}_{2}$ & BIIN_BRASS & $h P 6$ & $B 8_{2}$ \\
$\mathrm{Bi}-\mathrm{In}, \mathrm{In}-\mathrm{Pb}$ & $\alpha$ & TET_ALPHA1 & $t I 2$ & $A 6$ mod \\
$\mathrm{Bi}-\mathrm{Pb}$ & $\varepsilon$ & HCP_A3 & $h P 2$ & $A 3$ \\
$\mathrm{Bi}-\mathrm{Pb}, \mathrm{In}-\mathrm{Pb}$ & $(\mathrm{Pb})$ & FCC_A1 & $c F 4$ & $A 1$ \\
\hline
\end{tabular}

The resulting optimized phase diagrams of the constitutive binary systems Bi-In, $\mathrm{Bi}-\mathrm{Pb}$ and $\mathrm{In}-\mathrm{Pb}$ are shown in Fig. 1 .

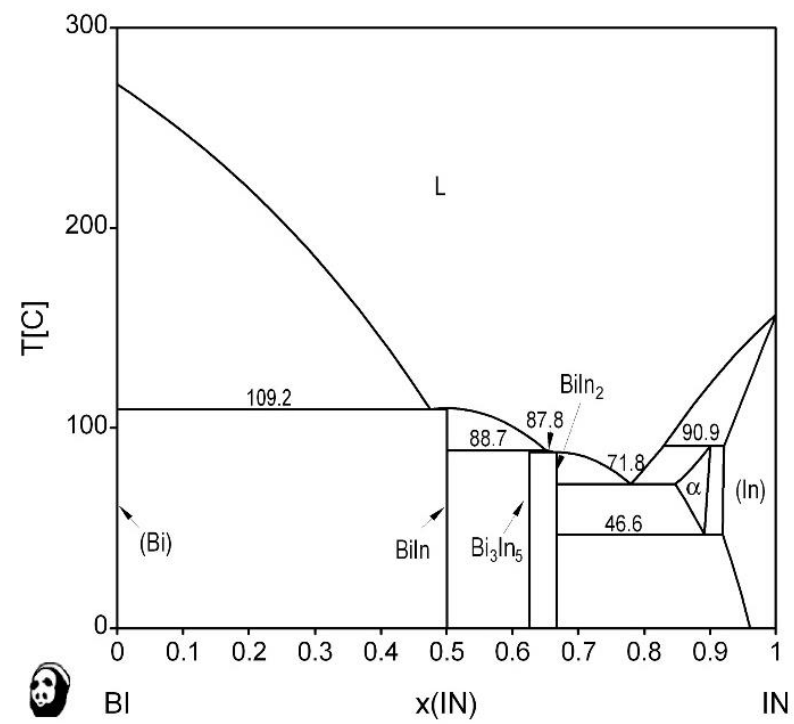

a) 


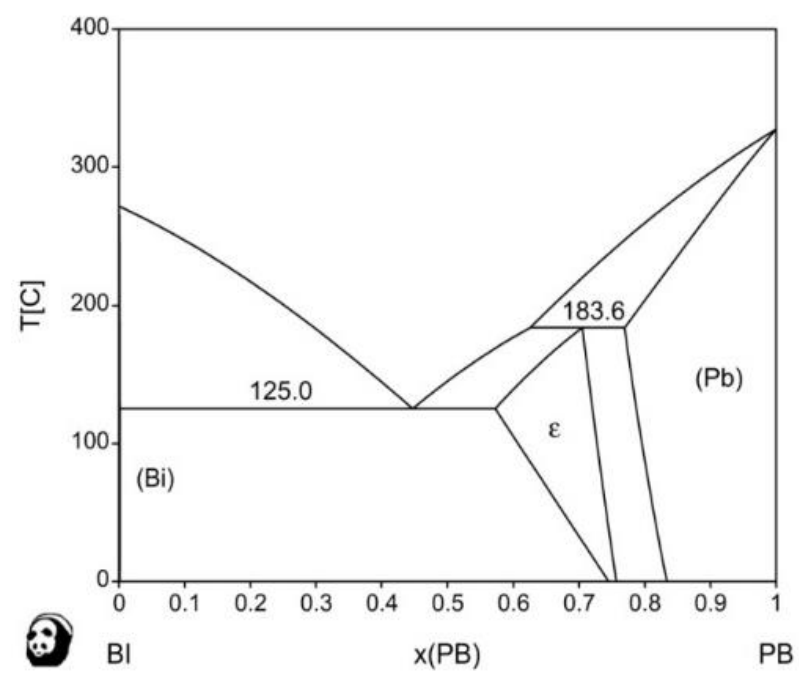

b)

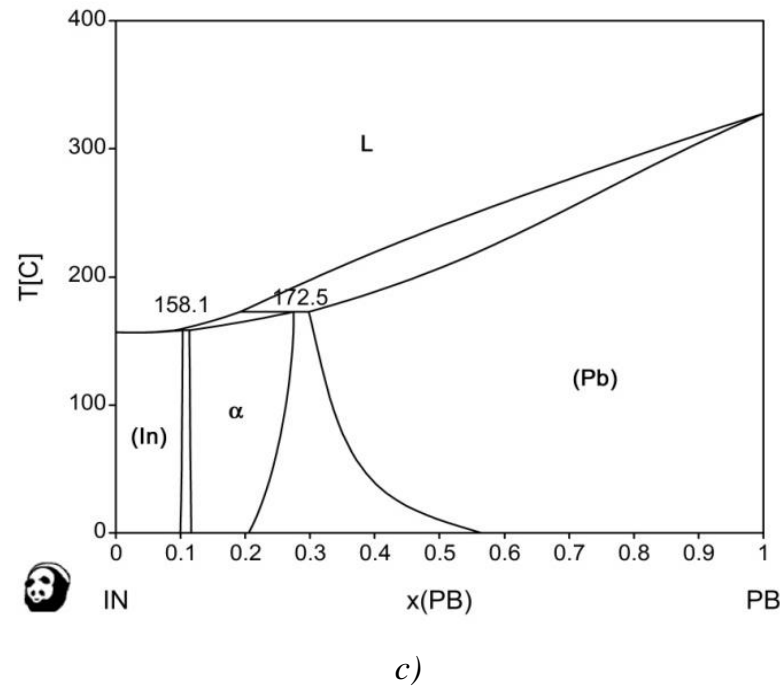

Fig. 1. Calculated phase diagrams of the constitutive binary systems based on thermodynamic parameters from Boa and Ansara [8]: a) Bi-In, b) Bi-Pb and c) In-Pb.

In regard to previous studies [8] and respective data presented in Table 1 and Fig. 1 we can see that in the Bi-In system (Fig. 1a) there are three stoichiometric compounds: BiIn, $\mathrm{Bi}_{3} \mathrm{In}_{5}$, and $\mathrm{BiIn}_{2}$. Additionally, there are also two solid solutions with almost no solubility [8], an In-rich tetragonal-A6, and a rhombo_A7 Bi-rich solid solution, as well as a tetragonal $\alpha \mathrm{A} 6$ mod phase.

In the $\mathrm{Bi}-\mathrm{Pb}$ system (Fig. $1 \mathrm{~b}$ ) there is an fcc- $\mathrm{A} 1 \mathrm{~Pb}$-rich solution, an intermetallic hcp-A3 phase $(\varepsilon-\mathrm{Pb} 3 \mathrm{Bi})$, and a rhombo_A7 Bi-rich solid solution. There is one eutectic reaction at $125^{\circ} \mathrm{C}$ and a peritectic reaction that occurs at $183.6^{\circ} \mathrm{C}$. In the case of $\mathrm{In}-\mathrm{Pb}$ system (Fig. 1c) there are no intermetallic compounds, only three solid solutions: an fcc- 
$\mathrm{A} 1 \mathrm{~Pb}$-rich solution, an intermediate $\mathrm{InPb}$ - phase, and an In-rich tetragonal-A6 solution. Two peritectic reactions take place in the system, one at $172.5{ }^{\circ} \mathrm{C}$ and the other at $158.1^{\circ} \mathrm{C}$.

Calculated liquidus projection of the $\mathrm{Bi}-\mathrm{In}-\mathrm{Pb}$ ternary system from Boa and Ansara [8] with a marked composition of the eutectic alloy studied in the present work (point $e_{1}$ ) is presented in Fig. 2.

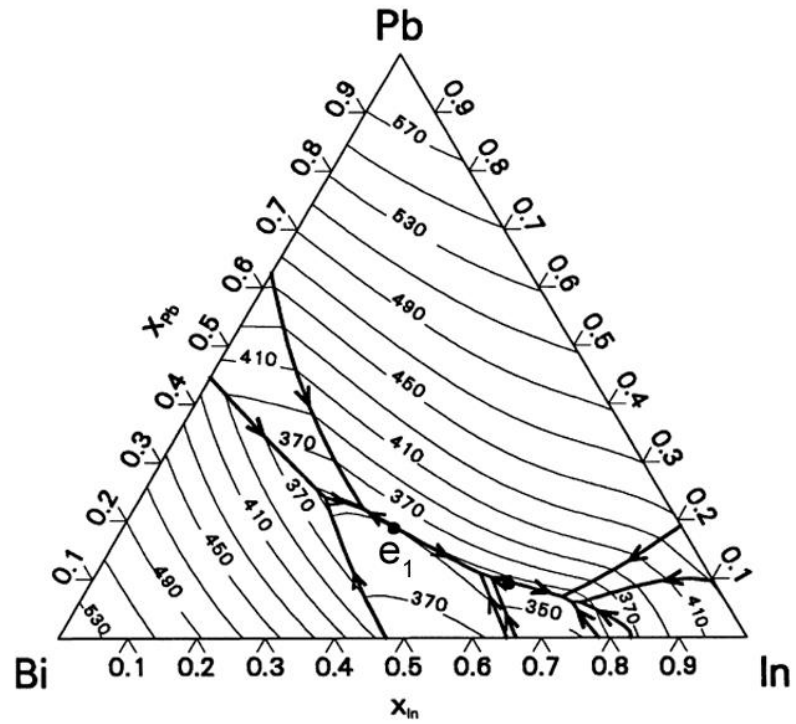

Fig. 2. Liquidus projection of the Bi-In-Pb ternary system from Boa and Ansara [8] with the marked composition of the eutectic alloy studied in the present work (point $e_{1}$ ).

\section{Results and discussion}

Microstructural analysis

The conducted microstructural and chemical analysis using SEM coupled with EDS has provided insight into the microstructure of the studied alloy, its overall chemical composition, and phase composition. Nominal and experimentally determined overall chemical compositions of the investigated alloy sample obtained by EDS area analysis are given in Table 2 .

Table 2. Nominal and experimentally determined overall compositions of the investigated alloy sample.

\begin{tabular}{|c|c|c|c|c|c|}
\hline \multicolumn{3}{|c|}{ Nominal composition (at.\%) } & \multicolumn{2}{|c|}{$\begin{array}{l}\text { Experimentally } \\
\text { composition with } \\
\text { uncertainties (at.\%) }\end{array}$} & \multirow{2}{*}{$\begin{array}{r}\text { determined } \\
\text { standard } \\
\mathrm{Pb}\end{array}$} \\
\hline $\mathrm{Bi}$ & In & $\mathrm{Pb}$ & $\mathrm{Bi}$ & In & \\
\hline 40 & 40 & 20 & $38.2 \pm 0.2$ & $39.5 \pm 0.4$ & $22.3 \pm 0.1$ \\
\hline
\end{tabular}


From the experimentally determined alloy composition presented in Table 2, the prepared alloy has somewhat higher $\mathrm{Pb}$ content and slightly lower contents of $\mathrm{Bi}$ and $\mathrm{In}$ compared to its nominal composition.

SEM micrograph, illustrating microstructure of the investigated $\mathrm{Bi}_{40} \mathrm{In}_{40} \mathrm{~Pb}_{20}$ (at. $\%$ ) alloy, is given in Fig. 3.

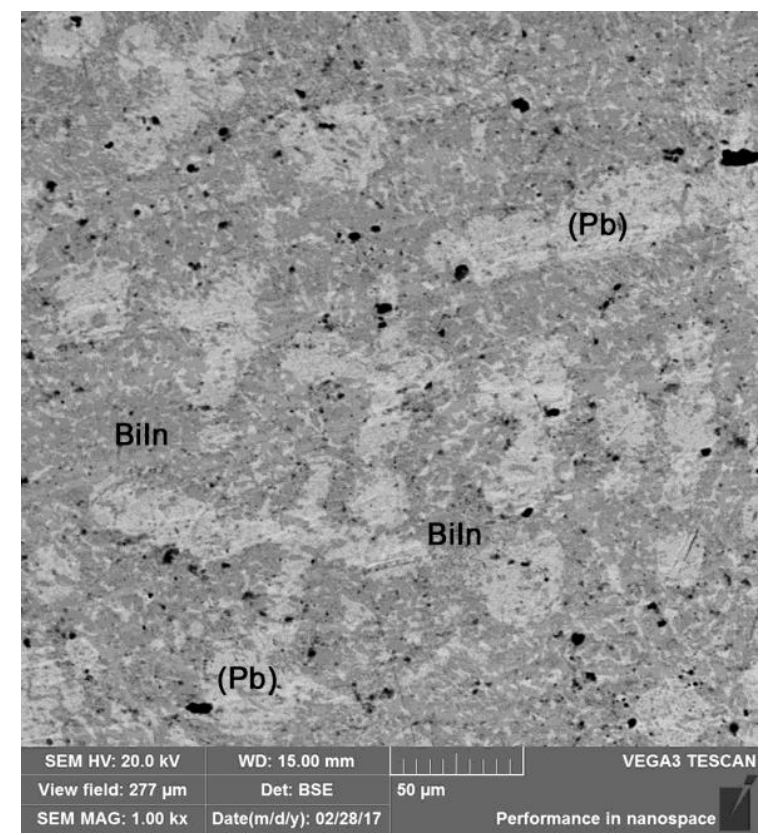

Fig. 3. SEM micrograph of the studied Bi-In-Pb alloy.

Two coexisting phases can be easily distinguished in the presented microstructure (Fig. 3.), and they were both subjected to EDS point analysis. Experimentally determined compositions of the coexisting phases for the investigated $\mathrm{Bi}-\mathrm{In}-\mathrm{Pb}$ alloy are shown in Table 3.

Table 3. Experimentally determined (SEM-EDS) compositions of coexisting phases in the studied alloy.

\begin{tabular}{lllll}
\hline $\begin{array}{l}\text { Overall exp. } \\
\text { composition (at.\%) }\end{array}$ & Phases & \multicolumn{3}{c}{ Compositions of phases (at.\%) } \\
\hline & $\begin{array}{l}\text { BiIn } \\
\text { (Grey }\end{array}$ & $49.3 \pm 0.1$ & $50.7 \pm 0.1$ & 0.0 \\
\hline Bi38.2In39.5Pb22.3 & $\begin{array}{l}\text { phase) } \\
\text { (Pb) }\end{array}$ & & & \\
\hline & $\begin{array}{l}\text { Bright } \\
\text { phase }\end{array}$ & $15.7 \pm 0.1$ & $26.7 \pm 0.3$ & $57.5 \pm 0.3$ \\
\hline
\end{tabular}


Following the obtained results of the EDS point analysis, the coexisting phases were identified. First, of the identified phases, which can be observed as the light phase in Fig. 3., represents $(\mathrm{Pb})$ solid solution, and it contains a high amount of lead (57.5 at.\%). The second, gray phase does not contain lead and has nearly the same concentrations of $\mathrm{Bi}$ and In. It represents BiIn intermetallic phase. In addition, from Fig. 3 can be noticed that the microstructure of the studied low-melting ternary alloy also includes a considerable amount of pores appearing as small dark spots.

\section{Thermal analysis}

The analysis of DSC results was done according to the literature recommendations regarding the interpretation of the heat flux DSC thermogram of metallic systems [10]. Solidus temperature was determined from the onset temperature of the DSC peak in the heating process. In the cooling process, the onset temperatures of both identified DSC peaks were considered as phase transition temperatures.

During the heating stage of measurements, only one sharp DSC endothermic peak was observed (Fig. 4a). This peak represents the start of the melting-solidus for the studied alloy. The solidus temperature, obtained as an average temperature from three repeated heating runs, is $76.3^{\circ} \mathrm{C}$. In contrast, DSC cooling curves exhibit two exothermic peaks (Fig. 4b). The broad peak at higher temperature represents liquidus temperature i.e. start of solidification of $(\mathrm{Pb})$ phase. The liquidus temperature, determined using DSC cooling curves, is $93.3^{\circ} \mathrm{C}$. The second, sharp DSC peak at lower temperature corresponds to the end of alloy solidification i.e. solidus. The average solidus temperature obtained from the three corresponding cooling runs is $61.2{ }^{\circ} \mathrm{C}$. The average heat of melting obtained from the heating runs is $16.9 \mathrm{~J} / \mathrm{g}$, and the average heat of solidification obtained from the cooling runs is $16.3 \mathrm{~J} / \mathrm{g}$.

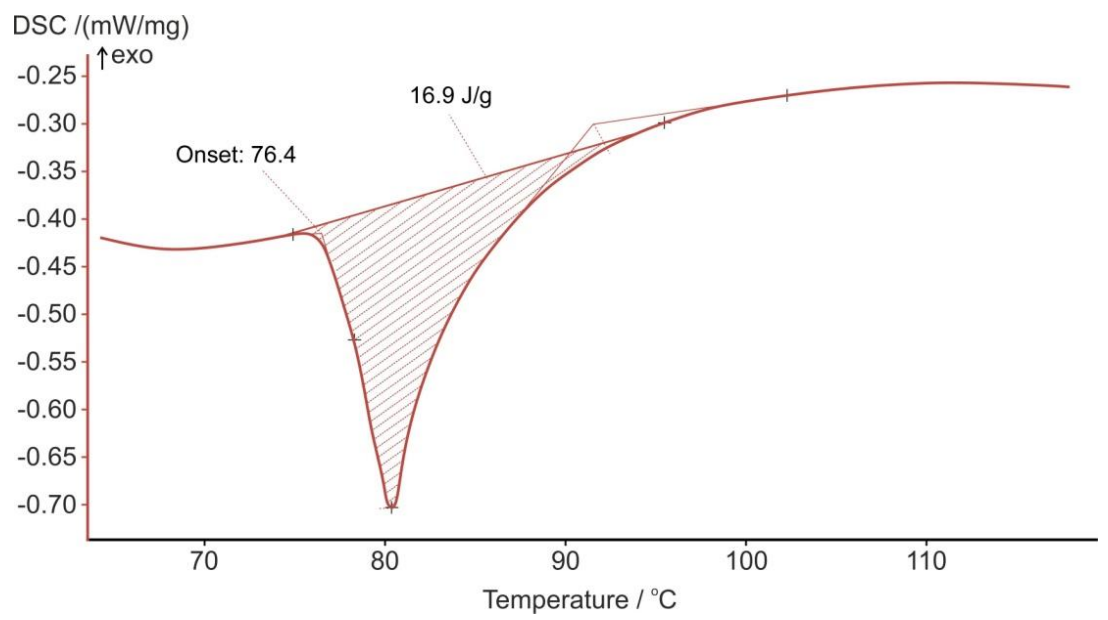

a) 


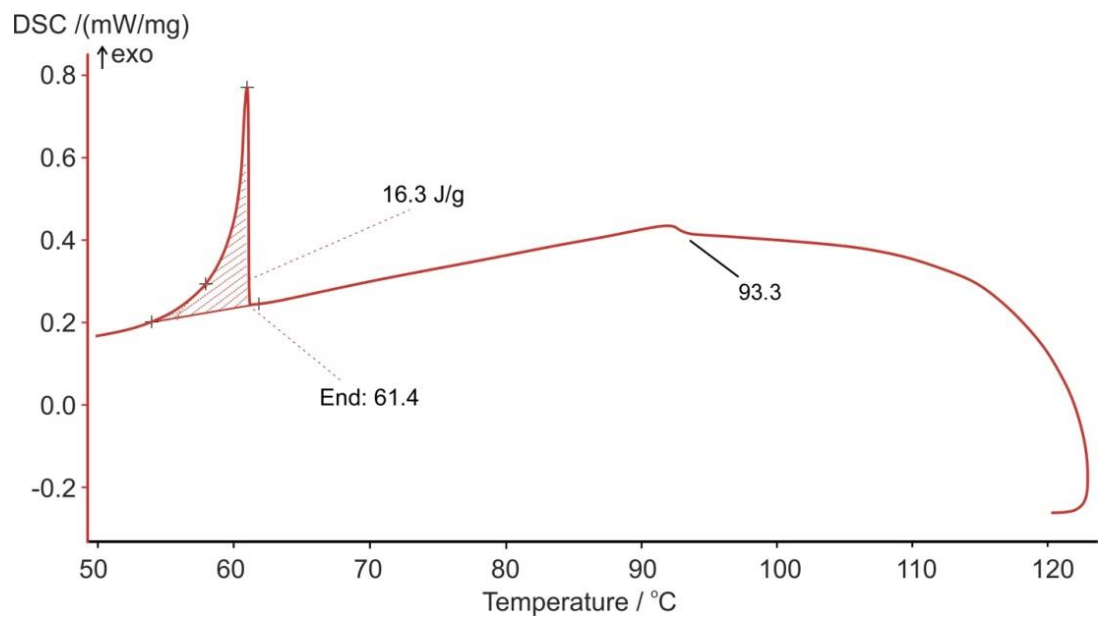

b)

Fig. 4. Third heating-cooling cycle for the studied Bi-In-Pb ternary alloy:

a) DSC heating curve; b) DSC cooling curve.

Comparison between experimental results and the results of thermodynamic calculation

Fig. 5 presents the calculated BiIn-Pb vertical section of the $\mathrm{Bi}-\mathrm{In}-\mathrm{Pb}$ ternary system with marked phase transition temperatures obtained from DSC heating and cooling measurements. According to the results of calculations, BiIn-Pb phase diagram is not quasi-binary because of the presence of a very narrow $\mathrm{L}+\mathrm{BiIn}+(\mathrm{Pb})$ three-phase field.

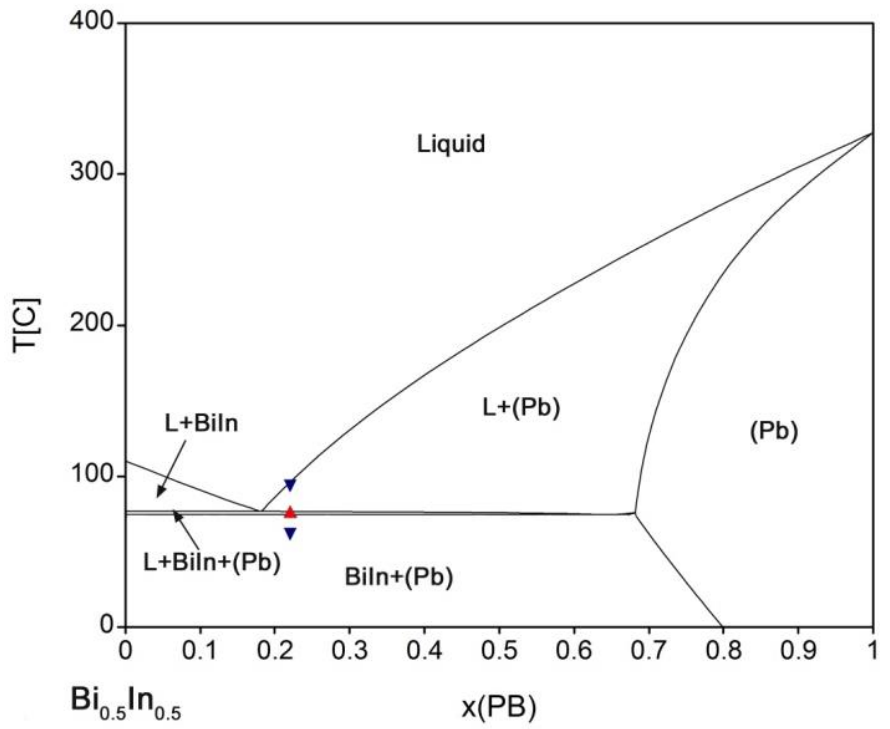

Fig. 5. Calculated BiIn-Pb vertical section with DSC results ( $\mathbf{\Delta}$ heating, $\mathbf{\nabla}$ cooling). 
Nevertheless, the calculated solidus temperature of the studied alloy is $76.0^{\circ} \mathrm{C}$, which is in excellent agreement with the experimentally determined value obtained during heating $\left(76.3^{\circ} \mathrm{C}\right)$. In contrast, the corresponding temperature value obtained during cooling $\left(61.2^{\circ} \mathrm{C}\right)$ is considerably lower. The observed difference between these two temperatures is most probably caused by the supercooling effect. Furthermore, from Fig. 5 can also be seen that the experimentally observed liquidus temperature is in excellent agreement with the results of the calculation.

\section{Conclusion}

Low-melting alloy with nominal composition $\mathrm{Bi}_{40} \mathrm{In}_{40} \mathrm{~Pb}_{20}$ (at.\%) was studied in this work. The microstructure and chemical composition of the prepared alloy was investigated using the SEM-EDS technique. It was found that the microstructure of the alloy includes BiIn intermetallic compound and $(\mathrm{Pb})$ solid solution phase. Experimentally determining chemical compositions (EDS) of the phases were compared with equilibrium phase compositions, and a reasonably close agreement was noticed.

Phase transition temperatures were measured by means of the DSC technique. As expected, the melting interval of the studied alloy is considerably below $100{ }^{\circ} \mathrm{C}$. The average solidus temperature of the heating runs was $76.3{ }^{\circ} \mathrm{C}$ and the average solidus temperature obtained from the corresponding cooling runs was $61.2{ }^{\circ} \mathrm{C}$. The evident difference between the two temperatures was ascribed to the supercooling effect as the most probable cause. The Liquidus temperature determined from the DSC cooling curves was $93{ }^{\circ} \mathrm{C}$. The average heat of melting obtained from the heating runs was $16.9 \mathrm{~J} / \mathrm{g}$, and the average heat of solidification obtained from the cooling runs was $16.3 \mathrm{~J} / \mathrm{g}$. When compared with the calculated phase diagram, the obtained experimental results show very close agreement and thus validate the used thermodynamic model.

\section{Acknowledgment}

The research presented in this paper was done with the financial support of the Ministry of Education, Science and Technological Development of the Republic of Serbia, within the funding of the scientific research work at the University of Belgrade, Technical Faculty in Bor, according to the contract with registration number 451-0368/2020-14/ 200131.

\section{References}

[1] M. Kamal, A.-B. El-Bediwi, R.M. Shalaby, M. Younus: J Adv Phys, 7 (2) (2015) 1404-1414.

[2] X.H. Yang, S.C. Tan, J. Liu: Int J Heat Mass Transf, 100 (2016) 899-907.

[3] D. Manasijević, Lj. Balanović, V. Ćosović, D. Minić, M. Premović, M. Gorgievski, U. Stamenković, N. Talijan: Metall Mater Eng, 25 (4) (2019) 325334.

[4] H. Ge, H. Li, S. Mei, J. Liu: Renew Sustain Energy Rev, 21 (2013) 331-346.

[5] S.I. Stel'makh, V.A. Tsimmergakl, I.A. Sheka: Ukr Khim Zh, 40 (1974) 471-473.

[6] S.I. Stel'makh, V.A. Tsimmergakl, I.A. Sheka: Ukr Khim Zh, 40 (1974) 762-764.

[7] H.L. Lukas, S.G. Fries, B. Sundman: Computational thermodynamics: the calphad method. Cambridge: Cambridge University Press; 2007.

[8] D. Boa, I. Ansara: Thermochimica Acta, 314 (1998) 79-86. 
[9] A. Dinsdale, A. Watson, A. Kroupa, J. Vrestal, A. Zemanova, J. Vizdal: COST 531-Lead Free Solders, 1, Atlas of Phase Diagrams for Lead-Free Soldering, European Report COST 531 Brussels: COST office, Belgium, 2008.

[10] W.J. Boettinger, U.R. Kattner, K.W. Moon, J.H. Perepezko: DTA and heat flux DSC measurements of alloys melting and freezing. In: Zhao JC, editor. Methods for phase diagram determination. Oxford: Elsevier; 2007. p. 152-222.

\section{(c) (†) Creative Commons License}

This work is licensed under a Creative Commons Attribution 4.0 International License. 